\title{
NCCN Policy Summit: Innovative Solutions to Drive Down Healthcare Costs: Implications for Access to High-Quality Cancer Care
}

Terrell Johnson, MPA ${ }^{1}$; Michelle McMurry-Heath, MD²; Ted Okon, MBA ${ }^{3}$; David Rubin ${ }^{4}$; and Robert W. Carlson, MD ${ }^{1}$

\section{ABSTRACT}

The cost of delivering high-quality healthcare in America now consumes $17.7 \%$ of the nation's gross domestic product according to Centers for Medicare \& Medicaid Services National Health Expenditure Data. With costs threatening to disrupt accessible and equitable care for patients, policymakers are reassessing all matters and functions of the healthcare system to excise waste, redundancies, and costly services. To explore this subjects' impact on oncology, NCCN hosted the NCCN Policy Summit: Innovative Solutions to Drive Down Healthcare Costs: Implications for Access to High Quality Cancer Care. This virtual summit featured multidisciplinary panel discussions and keynote addresses. Seeking to address barriers to low-cost, high-quality cancer care, panelists and keynotes presented innovative policy solutions to sustain highquality oncologic care at lower costs to the health system. This article encapsulates the discussions held during the summit and expounds upon salient points where appropriate.

J Natl Compr Canc Netw 2021;19(9):1021-1026 doi: 10.6004/jnccn.2021.7084

${ }^{1}$ National Comprehensive Cancer Network, Plymouth Meeting, Pennsylvania;

${ }^{2}$ Biotechnology Innovation Organization, Washington, DC; ${ }^{3}$ Community

Oncology Alliance, Washington, DC; and ${ }^{4}$ Memorial Sloan Kettering Cancer Center, New York, New York.
Since the early 2000 s, policymakers, payers, providers, and patients have emphasized the need to address the cost of healthcare. Particular attention has focused on oncology, with cancer-related healthcare spending eclipsing an annual expenditure of $\$ 183$ billion since $2015 .{ }^{1}$ In response to constituent pressures, lawmakers are proposing a series of legislative and regulatory changes to quell rising costs of care. For proponents of these bills, these initiatives represent streamlined solutions to address healthcare costs for patients and survivors. For opponents, these proposals oversimplify a complex healthcare system, threatening equal access to highquality, innovative, care. NCCN hosted the Virtual Policy Summit: Innovative Solutions to Drive Down Healthcare Costs: Implications for Access to High Quality Cancer Care on September 9, 2020, to discuss strategies to reduce the cost of care and the implications for oncology care. The virtual event hosted keynotes and multistakeholder discussions to examine opportunities and threats to high-quality cancer care posed by value initiatives to reduce healthcare delivery costs. This manuscript serves as a technical review of the discussions held during the summit.

\section{Lowering Costs in Healthcare and Implications}

The cost of treating cancer is placing immense economic pressure on healthcare systems and the patients they serve. ${ }^{2}$ Trend data now predicts that the total cost of treating cancer will surpass $\$ 246$ billion by 2030 , a projected $34 \%$ increase from 2015 figures. ${ }^{1}$ Costs associated with cancer treatment are also threatening the financial stability of patients and survivors, with annual out-of-pocket costs exceeding $\$ 5$ billion in 2018. ${ }^{2}$ A 2019 survey of cancer survivors reports that $25 \%$ are experiencing material hardship (difficulty paying bills or buying essentials). Of the surveyed survivors, $34 \%$ also reported psychologic hardships attributable to concerns about affording treatment and survivorship care. ${ }^{3}$ To discuss potential solutions to reducing the cost of cancer care, NCCN assembled a panel of stakeholders to highlight 
policy and practice recommendations to address health expenditures.

Policymakers have proposed several bills to address therapeutic cost during the 115th and 116th convenings of the United States Congress. Notable legislative vehicles include House Democrats' Elijah E. Cummings Lower Drug Costs Now Act (House Resolution 3) legislation that would allow the US Department of Health and Human Services (HHS) to negotiate prescription drug prices under the Medicare prescription drug benefit and to mandate that manufacturers pay rebates to the federal government if drug prices exceed inflation. ${ }^{4}$ Alternatively, Senate Republicans have introduced the Fair Accountability and Innovative Research Drug Pricing Act of 2019 (Senate Bill 1391), a proposal that would require manufacturers to notify HHS of and justify significant price increases. Unceremoniously, progress on these bills has been stalled by entrenched partisan differences on the role of government in price regulation. For the Prescription Drug Pricing Reduction Act of 2019 (Senate Bill 2543)—legislation similar to the Elijah E. Cummings bill-bipartisan support has stalled due to party differences on how the legislation should navigate rebating, price concessions for Part D plans, and price negotiation. ${ }^{5}$

Some members of the oncology community note alternative approaches to reducing therapeutic costs should receive more discussion in Congress. Notably, they acknowledge that establishing a competitive biosimilar market may garner more bipartisan support and general consensus among the healthcare community. Although abbreviated licensure pathways for biosimilars have existed since 2009, supporters of biosimilar transformation note that current policies have yet to successfully cultivate a strong market for product development and utilization. ${ }^{6}$ An analysis of commercial plans in 2020 seems to support this notion, finding that a mere $40 \%$ of major commercial health plans offer preferred coverage for biosimilar products on their benefit design. ${ }^{7}$ The solution may exist in reforming pharmacy benefit contracts; specifically, addressing modern pharmacy benefit manager (PBM) contract practices. Stakeholders note that the standards for contemporary contracts, including 3-year agreements and steep penalties for premature exit, make it difficult to adjust to an evolving therapeutic landscape. Furthermore, the existence of complex and varied definitions for "generic" and "brand-name" drugs, with exclusivity provisions for some products' use, leave providers confused about their ability to prescribe biosimilars, or limits their distribution altogether. ${ }^{6}$ The latest updates to the NCCN Clinical Practice Guidelines in Oncology (NCCN Guidelines; available at NCCN.org) indicating the appropriateness of substituting biosimilars for
FDA-approved innovator biologics may help to improve adoption, attesting to the safety and appropriateness of these products for skeptical payers and providers. ${ }^{6}$

Beyond the quandary of drug cost, development of transformative health information technologies (HITs) is also needed. Providers contend that what innovation has occurred in HIT has largely been proprietary, expensive, and incompatible with established hospital technology platforms. ${ }^{8}$ A survey of community oncologists reveals $62 \%$ find their electronic medical records increase staff workload. A majority of the surveyed oncologists also indicate their system significantly increased operating costs. ${ }^{9}$ For Navigating Cancer, an organization founded to improve the patient experience, the solution lies in developing technologies that streamline care management and reduce undesirable outcomes. A 2017 case study of the organization's own care management platformPatient Care Management-reduced beneficiary emergency visits by $6 \%$ and generated savings of $\$ 3.8$ million in 6 months. ${ }^{10}$ For WellMed, a healthcare delivery organization, focusing efforts on guideline adherence and dose optimization in its platforms has been fruitful. A Texas accountable care organization contracting with WellMed found that its beneficiaries group aged $\geq 65$ years lived longer than the average beneficiary aged $\geq 65$ years within the state. ${ }^{11}$ Looking forward, federal regulators should increase standards around HIT interoperability to reduce costs.

Although these policy and practice recommendations suggest the availability of effective strategies, most stakeholders agree that no single approach will solve the nation's healthcare cost issue. Rather, broader, communal efforts brought together through valuebased agreements (VBAs) and public-private partnerships will be most effective. ${ }^{6}$ Payers, PBMs, and manufacturers on the commercial side have begun to recognize the potential of VBAs to address this issue by exploring value-oriented payment and service delivery models for oncology. Regrettably, many attempts to develop VBAs remain unsuccessful and commercial negotiations are rarely disclosed to the public. An analysis of the 88 ongoing payer-manufacturer VBAs found that only $26 \%$ of the contracts publicly disclosed details. ${ }^{12}$ As a result of these challenges, many within the oncology community have turned to the Centers for Medicare \& Medicaid Services (CMS) for insights into successfully implementing models. "We still have an opaque system and we need more information and data to ensure that costs are reduced," reflected Gena Cook, founder of Navigating Cancer. "I'm really interested to see, as we move from the Oncology Care Model into the Oncology Care First model, what changes will happen." 


\section{Innovative Payment Models in Medicare and Medicaid}

The CMS Innovation Center (CMMI) invited oncology physician practices to participate in a new episode of care (EOC) model in 2015. Developed on the principles of patient-centeredness, evidence-based clinical practice guidelines, and continuous quality improvement, the Oncology Care Model (OCM) seeks to lower spend while maintaining the quality of care furnished under Medicare for 21 cancer bundles. Scheduled to sunset in June 2022 (the model has been extended due to COVID-19), results of the model have been eagerly awaited by those looking to glean insights into the future of alternative payment models. ${ }^{13}$ Lara Strawbridge, MPH, Director of the Division of Ambulatory Payment Models at CMMI, delivered a keynote address at the summit. Speaking 3 months after the release of CMS's report on OCM performance periods 1 through 3 , Ms. Strawbridge provided an overview of CMMI's findings and reflected on how insights from the concluded performance periods can improve future model development.

The conclusion of performance periods 1 through 3 reveal a number of complications yet to be resolved concerning the execution of VBAs in oncology. Chief among the obstacles illustrated in the report is the inconsistency with which OCM has been able to obtain savings per EOC. ${ }^{14,15}$ Organized by risk group, the OCM report demonstrates that low-risk cancer bundles managed by participating practices led to a $\$ 130$ increase in average total episodic payments (TEPs). Low-risk/lowintensity prostate cancer in particular observed an increase in cost, increasing the average TEP to $\$ 244$ per episode. ${ }^{15}$ The report also highlights that mechanics of the model have not yet driven value/cost-oriented selection of chemotherapy regimens, supportive care medications, or radiation therapy treatment as expected. Participating practices observed that Medicare Part D spending for beneficiaries increased by $\$ 160$ per episode. Altogether, these and other challenges have caused an overall net loss in Medicare spending to date for the innovation model. OCM resulted in approximately $\$ 155$ million in losses for Medicare by the end of performance period 3. Approximately $\$ 90$ million of those losses occurred in performance period 1 , and the remaining $\$ 65$ million in performance period $2 .{ }^{15}$

The report also identifies several opportunities in the model to save costs and improve care. ${ }^{14}$ Although lowrisk cancer bundles observed cost increases, high-risk cancer bundles, accounting for $66 \%$ of all OCM episodes, witnessed a reduction in costs averaging $\$ 430$ per episode. High-risk lung and small intestine/colorectal cancer in particular witnessed significant cost saving, reducing EOC by an average of $\$ 965$ and $\$ 742$ per episode, respectively. ${ }^{16}$ OCM also improved reduced costs for underrepresented populations with minority beneficiaries under OCM-participating practices, seeing an average decline in costs of $\$ 576$ per episode compared with $\$ 46$ per episode in savings for nonminority beneficiaries. Higher-risk participants also benefited from participation in the model. Patients with CMS Hierarchical Condition Category risk scores reflecting the presence of comorbidities such as hypertension, diabetes, or obesity observed an average decline in TEP of $\$ 344$ per episode. ${ }^{16}$

Looking ahead, CMMI sees opportunities to use these findings to improve future innovation. One question CMMI will have to answer is whether VBAs are beneficial as blanketed reform projects or as a precision tool. Some stakeholders, including former members of the Physician-Focused Payment Model Technical Advisory Committee, have noted that structuring future models to focus on subgroups such as high-risk populations or risk-specific tumor types may remove wasteful undertakings from the model. ${ }^{17}$ "We thought casting as broad a net around the patient population as possible would be most supportive in trying to really change the way that a practice operated as a whole," explained Ms. Strawbridge, "It's become increasingly evident just how different low- and high-risk episodes are. The low risk might be so low that there is no room for any significant reductions in spending." CMMI also recognizes an opportunity to use lessons learned from the COVID-19 public health emergency (PHE) to improve future models. ${ }^{14}$ Following the declaration of a national emergency, CMS released a series of waivers giving providers the latitude to care for patients remotely. It is possible that a number of these regulatory flexibilities, including telehealth, may assist in controlling cost. The PHE may also change practices' perspectives about alternative payment models and their willingness to take downside risk. [Editor's note: the information above was up-todate at the time of the virtual summit; in the interim, new data on performance periods 4 and 5 have become available. See innovation.cms.gov for more information.]

\section{Best Practices for Succeeding in Commercial VBAs}

Like CMS, commercial insurance entities are also attempting to reduce costs and improve quality through innovative reimbursement agreements and practice transformation projects. Although these payers and participating providers note that more conversations regarding value-based reimbursement models are occurring, adoption of value-based enterprises that include downside risk - a term used to describe reimbursement agreements that include financial responsibility on the part of care delivery organizations for their beneficiaries' health outcomes and care experience- 
remains sluggish. A policy brief published by Catalyst for Payment Reform finds that $89 \%$ of value-oriented payments only offer providers financial upside. ${ }^{18}$ Members of the oncology community hold a number of issues attributable to the slow adoption of downside risk, including infrastructure barriers, performance measurement discrepancies, and historical inexperience and lack of guidance. ${ }^{19} \mathrm{NCCN}$ assembled a fireside chat consisting of 2 contracting and data analytics specialists from NCCN Member Institutions. Sitting with panel moderator Cliff Goodman, the 2 speakers discussed the present challenges within developing commercial agreements and considerations for improvement of future VBAs.

Contract and analytics specialists at the summit highlighted that the principal barrier to successful adoption of VBAs is finding consensus on metrics with commercial payers. Conversations between providers and payers/employer groups run the risk of breaking down when there is a lack of agreement on an appropriate metric to measure success. ${ }^{19}$ Contracting and analytics specialists also noted that finding consensus on metrics becomes more convoluted when considering the varying ways in which commercial payers can define or quantify a particular metric. ${ }^{19}$ In lieu of these challenges, participants of the discussion highlighted the importance of establishing trust prior to contract negotiations. One best practice is to develop regional/local association groups for the purposes of sharing information and perspectives on value-based enterprises in advance of negotiations. ${ }^{19}$ For the University of Michigan Rogel Cancer Center, the pursuit of trust and consensus with payers led to participation in the American College of Surgeons Commission on Cancer (CoC). Comprising representatives from $>50$ cancer-related organizations, the coalition seeks to improve the quality of life and survival of patients with cancer. One initiative launched by $\mathrm{CoC}$ membership works to establish standards for quality metrics and collects data from CoC-accredited healthcare settings to measure quality performance. ${ }^{19}$

Contract experts also cited barriers regarding data administration and performance evaluation; markedly, the significant role antiquated claims technology plays in preventing health systems from the timely analysis of performance data. ${ }^{19}$ "Some of the challenge relates to claims systems and hospital billing systems, which are really designed for fee-for-service," reflected David Rubin, Director of Health Outcomes \& Quantitative Analytics for Memorial Sloan Kettering Cancer Center. "Our electronic medical records were designed for clinical purposes, not data analytics or value-based payment. How do you run a real-time decision-making enterprise that way?" Although commercial insurers' average claims error rate has declined from $19 \%$ to $<7 \%$ since 2016, the remediation process costs health systems substantial resources..$^{20} \mathrm{~A}$ tactic for circumventing this barrier can be found in the third-party EHR market, where a number of vendors have created add-ons to existing billing systems. Although effective, members of the discussion note that this resolution still lacks the permanence providers need to feel safe in their billing system's ability to execute value-based enterprises. ${ }^{19}$ Future EHR systems must be developed with this barrier in mind and supply health systems with the tools they need to survive in value-based agreements. Contract experts note that of considerable importance is the need for EHRs to include improved performance evaluation tools.

Within these best practices, proponents cited the importance of collaboration and establishing trust. Contract specialists note that the politically charged atmosphere surrounding healthcare cost discussions have left many parties mistrustful of one another. However warranted or unwarranted that mistrust may be, stakeholders must recognize that innovating through VBAs demands collaboration by all interests within the system to ensure agreements successfully reduce costs and improve patients' lives. ${ }^{19}$ The threat of not collaborating puts at risk the interest of all organizations that serve patients with cancer. ${ }^{19}$ "The cost of healthcare is going through the roof, and everybody has a vested interest in seeing it be stabilized," emphasized Thomas Daly, Director of Managed Care at University of Michigan. "And that, in and of itself, should be enough to get people to the table."

\section{Access and Equity in the Age of COVID}

On June 24, 2020, NCCN Chief Executive Officer, Dr. Robert Carlson, published an op-ed in Statnews. The editorial highlighted the disparate health outcomes for Black Americans and proclaimed the need for equitable care and provider representation to achieve unbiased cancer prevention, diagnosis, treatment, survivorship, and research among racial and ethnic minorities. ${ }^{21}$ Although undoubtedly a social justice issue, inequity in healthcare also exacts a considerable financial toll. A 2011 study estimated that the costs of eliminating health disparities in the US healthcare system could save as much as $\$ 230$ billion in direct care costs. The same analysis, when reviewing data from the Medical Expenditure Panel Survey, found that indirect costs associated with illness and premature death cost the US healthcare system $\$ 1$ trillion over a 4 -year period..$^{22}$ To conclude the NCCN Virtual Policy Summit, NCCN hosted Dr. Michelle McMurry-Heath, Chief Executive Officer of the Biotechnology Innovation Organization (BIO). Leading an advocacy organization representing $>1,000$ biotechnology companies, Dr. McMurry-Heath highlighted the role biotechnology companies anticipate playing in the 
advancement of equity and the importance of keep equity front-of-mind in the pursuit of reduced healthcare expenditures.

Since the death of George Floyd, sectors of the American economy have engaged in deep conversations about systemic racism. For healthcare, the specter of COVID-19 has made that discussion more essential. According to data from the CDC, nonHispanic Black Americans are more than 4 times as likely as non-Hispanic White Americans to be hospitalized with COVID-19. ${ }^{23}$ In response, manufacturers have launched partnerships with the US government to accelerate the development of vaccines and consider distribution frameworks that prioritize those most impacted by the virus, including Americans with disabilities, the elderly, and racial/ethnic minorities. One enterprise, Operation Warp Speed, has observed considerable success, helping researchers launch $>700$ vaccine antibody therapy and antiviral clinical development programs just months after the pandemic commenced. ${ }^{24}$ For the biotechnology industry, this type of progress highlights the value of increased collaboration between government and industry partners on healthcare-related issues. Biotechnology stakeholders note that this type of collaboration should be applied to the broader issues of costs and equitable access in American healthcare. ${ }^{24}$

To these ends, BIO launched the BIOEquality Agenda in August 2020. Under this program, BIO is engaging in a national effort to counteract systemic inequality by partnering with organizations to advance equitable care delivery, expand opportunities in biotech for minorities, and invest in the careers of minority researchers and investigators. ${ }^{24}$ Since launch, the organization has hosted a virtual COVID-19 summit to discuss how the industry can advance the program's goals, beginning with COVID-19 vaccines. The 2-day event included the presence of many government representatives, including former White House Coronavirus Task Force Coordinator, Ambassador Deborah Birx, and Dr. Robert Kadlec, Assistant Secretary for Preparedness and Response at HHS. In research, BIO is looking to address the lack of diversity in clinical trial enrollment as well. ${ }^{24}$ A report from the FDA found that of the 46,391 patients who participated in the approval of 48 novel drugs through the Center for Drug Evaluation and Research, only $9 \%$ were African American. ${ }^{25}$ BIO has developed partnerships with the National Association of Black Churches and the National Urban League to build communication channels with communities of color and increase awareness of the benefits of trial participation. The organization is also working with its members to revise trial eligibility criteria. ${ }^{24}$

One concern, however, is the promotion of legislative and regulatory efforts that tie the cost of therapeutics in America to foreign countries. Several initiatives, including the FDA's final rule on the Importation of Prescription Drugs, CMS's International Pricing Index (IPI) Model, and most recent Most Favored Nation Price executive order, have all looked to remedy the challenge of mounting healthcare expenditures. For members of the biotech industry, these proposals risk increasing inequity due to lack of consideration for how proposed changes may impact patient populations that already experience barriers to innovation. ${ }^{24}$ Alternatively, these stakeholders propose working with the biotechnology through private-public partnerships to identify opportunities to reduce disparities in care and access while simultaneously reducing costs.

\section{Conclusions}

Unrestrained, the cost of cancer care in America poses a significant threat to patients' ability to access highquality care and the capacity of the healthcare system to effectively deliver it. Oncology stakeholders need to show policymakers that biosimilars, value-based reimbursement models, innovative technologies, and equitable care initiatives represent opportunities to lower expenditures while preserving a high standard of care. With the Biden-Harris Administration poised to adopt the issue of healthcare as a cornerstone of their agenda, it is imperative that members of the cancer community work in concert to promote the ability of the aforementioned policy proposals to remake a more transparent, equitable, and affordable healthcare system.

Submitted February 19, 2021; final revision received July 26, 2021; accepted for publication July 27, 2021.

Disclosures: The authors have disclosed that they have not received any financial considerations from any person or organization to support the preparation, analysis, results, or discussion of this article.

Correspondence: Terrell Johnson, MPA, National Comprehensive Cancer Network, 3025 Chemical Drive, Suite 100, Plymouth Meeting, PA 19462. Email: TJohnson@nccn.org

\section{References}

1. Mariotto AB, Enewold $L$, Zhao J, et al. Medical care costs associated with cancer survivorship in the United States. Cancer Epidemiol Biomarkers Prev 2020;29:1304-1312.

2. American Cancer Society; Cancer Action Network. The Costs of Cancer: 2020 Edition. Accessed July 21, 2021. Available at: www.fightcancer.org/sites/ default/files/National\%20Documents/Costs-of-Cancer-2020-10222020.pdf

3. Ekwueme DU, Zhao J, Rim SH, et al. Annual out-of-pocket expenditures and financial hardship among cancer survivors aged 18-64 years — United States, 2011-2016. MMWR Morb Mortal Wkly Rep 2019;68:494-499.

4. Elijah E. Cummings Lower Drug Costs Now Act, HR 3, 116th Cong (2019-2020). Accessed July 21, 2021. Available at: https://www.congress. gov/bill/116th-congress/house-bill/3 
5. Wynne B, Llamas A. New Legislation to Control Drug Prices: How Do House and Senate Bills Compare? The Commonwealth Fund website. Accessed July 21, 2021. Available at: www.commonwealthfund.org/blog/ 2019/new-legislation-control-drug-prices-how-do-house-and-senate-billscompare

6. Perspectives on the Future of Lowering Costs in the American Healthcare System and Implication's for the Oncology Community. Panel Discussion at the NCCN Policy Summit: Innovative Solutions to Drive Down Healthcare Costs: Implications for Access to High Quality Cancer Care; September 9, 2020.

7. Chambers JD, Lai RC, Margaretos NM, et al. Coverage for biosimilars vs reference products among US commercial health plans. JAMA 2020;323: 1972-1973.

8. Graetz I. The health IT special issue: enduring barriers to adoption and innovative predictive methods. The Am J Manag Care 2020;26:19.

9. Kim J. Challenges to EHR optimization for cancer programs-workload, cost, and interoperability. Association of Community Cancer Centers website. Accessed July 21, 2021. Available at: www.accc-cancer.org/acccbuzz/blogpost-template/accc-buzz/2017/05/30/challenges-to-ehr-optimization-forcancer-programsworkload-cost-and-interoperability

10. Barkley R, Soobader MJ, Wang J, et al. Reducing cancer costs through symptom management and triage pathways. J Oncol Pract 2019;15: e91-97.

11. Phillips RL Jr, Bronnikov S, Petterson S, et al. Case study of a primary carebased accountable care system approach to medical home transformation. J Ambul Care Manage 2011;34:67-77.

12. Branning $G$, Lynch $M$, Hayes K. Value-based agreements in healthcare: willingness versus ability. Am Health Drug Benefits 2019;12:232-234.

13. Oncology Care Model. CMS.gov. Accessed July 21, 2021. Available at: innovation.cms.gov/innovation-models/oncology-care

14. Innovative Reimbursement Models in Medicare and Medicaid. Keynote at the NCCN Policy Summit: Innovative Solutions to Drive Down Healthcare Costs: Implications for Access to High Quality Cancer Care; September 9, 2020.

15. CMS Perspective: Oncology Care Model (OCM) second annual evaluation report and next steps on oncology innovation. July 2020. Accessed July 21,
2021. Available at: innovation.cms.gov/data-and-reports/2020/cmsperspective-ocm

16. Evaluation of the Oncology Care Model: Performance Period 1-3 Appendices. Accessed July 21, 2021. Available at: innovation.cms.gov/ data-and-reports/2020/ocm-evaluation-annual-report-2-appendices

17. Miller HD. Accelerating value-based payment and supporting patientcentered care through more efficient and effective innovation. Accessed July 21, 2021. Available at: https://www.chqpr.org/

18. 2018 National Scorecard on Commercial Payment Reform. Catalyst for Payment Reform website. Accessed July 21, 2021. Available at: www. catalyze.org/product/2018-national-scorecard/

19. Getting Providers and Payers to the Other Side: Best Practices for Succeeding in Commercial Value-Based Agreements. Panel Discussion at the NCCN Policy Summit: Innovative Solutions to Drive Down Healthcare Costs: Implications for Access to High Quality Cancer Care; September 9 2020.

20. Morse S. If only the claims were clean: payers, providers lose big on inaccuracies, poor workflows. Healthcare Finance website. Accessed July 21, 2021. Available at: https://www.healthcarefinancenews.com/news/ifonly-claims-were-clean-payers-providers-lose-big-inaccuracies-poorworkflows

21. Carlson RW. Treatment barriers create racial disparities in cancer care. They need to come down. Accessed July 21, 2021. Available at: https://www. statnews.com/2020/06/24/cancer-care-racial-disparities-dismantlebarriers/

22. LaVeist TA, Gaskin D, Richard P. Estimating the economic burden of racial health inequalities in the United States. Int J Health Serv 2011;41:231-238.

23. Centers for Disease Control and Prevention. Key Updates for Week 2, ending January 16, 2021. Accessed February 1, 2021. Available at: https:// www.cdc.gov/coronavirus/2019-ncov/covid-data/covidview/index.html

24. Access and Equity in the Age of COVID. Keynote at the NCCN Policy Summit. Innovative Solutions to Drive Down Healthcare Costs: Implications for Access to High Quality Cancer Care; September 9, 2020

25. U.S. Food \& Drug Administration. 2019 Drug Trials Snapshots: Summary Report. Accessed July 21, 2021. Available at: https://www.fda.gov/drugs/ drug-approvals-and-databases/drug-trials-snapshots 